\title{
Mega Events, Fear, and Risk: Terrorism at the Olympic Games
}

\author{
Kristine Toohey \\ Griffith University \\ Tracy Taylor \\ University of Technology, Sydney
}

\begin{abstract}
Since 1972, there has been an association between terrorism, violence, and the Olympic Games. The events of September 11, 2001, however, clearly reescalated concerns about the Games being a terrorist target. This conceptual article discusses the theories of the risk society and the precautionary principle to understand and interpret how visitors to the most recent Summer Games, Athens 2004, framed their decision to attend. Consistent with risk theory, a strong public and financial commitment to safety at the Games was evident, with the organizers undertaking wide-ranging large-scale risk management initiatives. Athens attendees, while displaying tenets of risk aversion and engagement with a discourse of fear, also showed resilience, resistance, and indifference to potential terrorism threats. Implications for both theory and practice are noted.
\end{abstract}

Since September 11, 2001 (9/11), the increased threat of terrorism has brought risk management to the forefront of mega-sport-event planning and has resulted in a range of new security measures for sport spectators and tougher safety standards for organizers. Although there has been considerable scholarly enquiry into the causes and effects of terrorism as it relates to tourism and events in general (cf. Hall, Timothy, \& Duval, 2003), there has been a lack of academic research investigating the emotional responses of sport event spectators to the threat of terrorism and how this response impacts management.

Terrorist-based risk associated with sport spectating in the 21st century is not without substance, because there have been 168 terrorist attacks related to sport between 1972 and 2004 (Clark, 2004; Kennelly, 2005). These data indicate that terrorism at sporting events is not just a post-9/11 problem. The intensity of media and governmental moral panics and event organizers' responses to terrorism since 9/11, however, have brought the issue to the attention of the world in a manner similar to the aftermath of the 1972 Munich Olympic attack.

Toohey is with the Department of Tourism, Leisure, Hotel and Sport Management, Griffith Business School, Griffith University, Gold Coast 4222, Australia. Taylor is with the Faculty of Business, University of Technology, Sydney, Lindfield NSW 2070, Australia. 
Atkinson and Young (2002) provide a general explanation of the nexus between sport and terrorism:

For many reasons, individual terrorists or terrorist organizations might find suitable targets in athletes participating in games, spectators attending the events, or selected corporate sponsors of sports contests. Especially in those situations where athletic contests draw sizeable international audiences in geographical settings already embroiled in strife, sport can be utilized as a vehicle for political sparring, and waging and disseminating forms of political violence against others. (p. 54)

Other more general connections can also be drawn and, in some extreme cases, sport spaces have chillingly been converted to sites of state-sponsored terrorism. For example, in Afghanistan, Kabul's main sport venue, Ghazi Stadium, was used by the Taliban to carry out public executions during halftime at sporting events. In addition, engaging in military-style physical training has been an important part of some terrorists' preparation (Toohey \& Taylor, 2006).

Despite the numerous direct and indirect links between sport and terrorism, academic inquiry into sport violence has primarily concentrated on the causes and effects of player and spectator violence (Atkinson \& Young, 2002). Moreover, most of these studies have been located in discourses of sport sociology or psychology and criminology, investigating the cognitive, affective and overt behavioral aspects of violence. Implications drawn for sport management have primarily been associated with crowd control, risk management and athlete management (cf. Kennelly, 2004; Rubin, 2004; Whisenant, 2003). There are, however, other broader environmental consequences of the relationship between violence (especially terrorism) and sport, for example, sociocultural factors, which impact the management of sport events and, as such, need to be better understood by sport management practitioners and academics alike. Amis and Silk (2005, p. 359) suggest that, "in addressing an organizationally based problem - an understanding of the context in which the research takes place is vital." Adding to this external focus, Frosdick (1999, p. 138) suggests that, "cultural analysis has an important role to play in the study of management in general, including the management of public safety and order." One aspect of understanding the context and culture of terrorist risk at sport events is to begin understanding "risk as a multitude of perceptions about the source and level of threat or danger" (Frosdick, 1999, p. 38).

Accordingly, examining the sport spectator's perceptions of the risk of terrorism needs to be grounded in understanding relevant theoretical and contextual literature, which can involve other disciplines. As Pitts (2001, p. 1) argues, sport management needs to expand its dominant paradigms, "beyond the passive acceptance of constructed definitions and positions about sport management and its content without question. Thus, it is both necessary and prudent to view sport management beyond the traditional view of managing sports." Similarly, Skinner and Edwards (2005, p. 416) advise that, "sport management researchers should be encouraged to take more methodological risks and embrace more eclectic research approaches."

We propose that, by understanding the 'risk society' and what this means in for sport event management, we can challenge dominant sport management paradigms and provide an emergent theoretical background by which to understand 
the impact of terrorism on sport event spectators. This also has application for sport event practitioners. Elliot, Frosdick, and Smith (1999) believe "the stadia industry has something to learn ... from the research that has been carried out by academics in the areas of safety culture and crisis management" (p. 26). Through using the concept of the risk society we are able to identify and situate related sport management issues, such as terrorism, in a broader context. We do so in this article by locating these discussions of terrorism and risk alongside a contextual overview of terrorism risks at Olympic Games from 1972 onwards.

The context of terrorism has relevance to sport events, and the potential and realized impacts on the management of contemporary sport events have been profound (Taylor \& Toohey, 2006). As such, the lack of published research in this area is surprising. In this article, we use the conceptualization of risk to frame the reactions, expectations, and perceptions of spectators to the post $9 / 11$ security environment and to analyze resultant measures to deal with possible terrorist threats. This is a different theoretical perspective from the "positivist orientation" that dominates much of sport management research (Frisby, 2005, p. 4), and it provides a basis from which to interrogate how Western society's embracement of the "precautionary principle" and the growth of the risk society underpin the organization of megasporting events (Toohey, 2006). This alternative approach has meant that security measures no longer only involve what Coaffee and Wood (2006) describe as a "rings of steel" mentality, characterized by regulatory management, fortification, and surveillance, as was instituted at the 1976 Olympic Games in response to the 1972 terrorist attack. Its primary principle was to categorize, divide, and control Olympic sites. More recently, the Olympic security paradigm has shifted. It now augments the rings of steel attitude, to one that has also encouraged resilience, both physically and managerially, through more counterterrorism measures and dispersing security responsibilities to different agencies and governments, rather than just organizing committees (Coaffee \& Wood, 2006).

\section{Terrorism}

Terrorism has wide-reaching ramifications in social, political, and financial terms. For example, in the latter domain, during 2005, the global cost of fighting terrorism was estimated to be about US\$191 billion, and this amount is predicted to triple within a decade (Agence France-Presse, 2005). In regard to sport, "it has been estimated that organizers of sporting events worldwide spend over $\$ 2$ billion per annum on security, although in years where 'blanket security' is required for major events this figure can rise to \$6 billion” (Coaffee \& Wood, 2006, p. 513).

In its modern guise, terrorism dates from 1968, the year that hijackings and bombings of planes first captured the attention of world media and governments. Three factors have aided its territorial and hegemonic escalation: "the expansion of air travel; the wider availability of televised news coverage; and broad common political and ideological threats" (Kiras, 2005, p. 482).

There is still no universally accepted definition of terrorism; however, scholars believe there are elements common to most terrorist acts. First, they are usually committed by groups who do not possess the political power to change policies they believe are insupportable. Second, terrorists often justify their acts on ideological 
or religious grounds, arguing that they are responding, not to existing laws, but trying to right to a greater wrong or promoting a greater good. Third, targets are selected to maximize negative psychological effects on societies or governments (Constitutional Rights Foundation, 2006). Richardson (2006) points out that terrorists have both long- and short-term motivations. In terms of immediate objectives "they want to exact revenge, they want to acquire glory and they want to force their adversary into a reaction" (Richardson, 2006, p. 14).

For these reasons, it is logical that terrorists will choose methods of mass destruction, such as bombings, and target transport or places where people gather, such as sport stadia. Terrorists also plan their acts to get as much media exposure as possible thus giving attention to their cause (Whisenant, 2003). These reasons explain why mega sport events such as the Olympic Games are seen as possible terrorist targets. Tarlow (2002) cataloged a range of logistical reasons why sport events might appear to be attractive targets. Spectator numbers and flows make it difficult to physically identify terrorists; the proximity of events to transportation hubs allow quick escape routes; and event-associated hospitality sectors (for example, live sites, hotels, and restaurants) have the potential to be affected, spreading the reach and impact of a sporting terrorist incident (Hadfield, Toohey, Taylor, \& Mason, 2004).

Just as the media play a central role in the broadcasting of terrorist attacks and their aftermath, the media also can be a major influence in shaping government policy in relation to disaster planning and management (Trim \& Caravelli, 2007). In consequence, as a countermeasure to recent terrorist activity, a range of risk management strategies have been implemented by relevant governments and event organizers to prevent possible attacks. In terms of the Olympic Games, the variety of tactics used have included the deployment of Olympic police and military units to dedicated Olympic units to patrol the host city and country; the creation of Olympic Intelligence Centers to monitor information and coordinate responses; the formation of international Olympic Security task forces to share information between nations; the increasing use of surveillance, including digital surveillance to augment people; and the implementation of progressively more complex technology to prevent unauthorized access (Johnson, 2006). These measures have meant that sport event organizers have had to work closely with relevant government security agencies and have had to balance what Johnson (2006) refers to as the push-pull dilemma of "limited budget versus infinite demands" (p. 14). The resultant success or otherwise of these measures will be described in greater detail later in the article.

\section{Theoretical Framework}

The importance of risk in and to society is not a static phenomenon. Risk refers to dangers that we seek to actively identify, confront and control (Giddens, 1998). Although fears about personal safety are not new, the global dimensions of fear and associated risk are of far more recent origin.

According to Frosdick (1999) the modern concept of risk originated in the 17 th century and grew from the study of probabilities associated with gambling. In the next century, risk assessment was the foundation of the maritime insurance 
business and one century later it was incorporated into the study of economics. In the 20th century, the notion of risk took on more pessimistic connotations and was primarily associated with how to avoid genuine or perceived hazards. In recent decades, risk has become increasingly prominent as a litigious concept: It has also been politicized and now affects how we perceive our daily lives and our future. Durodié (2004a) observed that, "in recent times the concept of risk itself has gradually altered from one that captured possibility and engagement in the active sense of 'taking a risk', to one that increasingly reflects a growing sense of doom and distance from events, as evidenced in growing reference to the passive phrase of 'being at risk.' Risk used to be a verb. Now it has become a noun" (p. 14). Risks have also become more global.

\section{The Risk Society}

The work of Ulrich Beck (1992), presented in his seminal work, Risk Society: Towards a New Modernity, first conceptualized a new phenomena of environmentally based global risks; the subsequent growing public commitment to preventing further risks; the effects of new risks on people's world views; and the lobby/government/media-driven resultant moral panics. Beck (1992) termed the outcome of this combination of factors as "the risk society." Although he was primarily concerned with global risks that resulted from environmental catastrophes, Beck's dystopian viewpoint has since been broadened to encompass modernity's more general preoccupation with risk (cf. Spence, 2005). Contemporary "risk society is based on the view that more and more aspects of our lives are framed by an awareness of the dangers confronting humankind at the individual, local and global level, and the need to develop strategies to confront these dangers" (Kenny, 2004, p. 1)

Importantly, risks might only exist in our scholarly knowledge of them (i.e. through dire predictions of the future), that is, they might or might not actually occur. As Beck (1992) argued, this means that

They can thus be changed, magnified, dramatized or minimized within knowledge, and to that extent they are particularly open to scientific definition and construction. Hence, the mass media and the scientific and legal professions in charge of defining risks ... [have] key social and political positions. (p. 23)

Knowledge, or rather our predictions based on assumed knowledge leading to risk assessment thus assumes a new significance, can result in moral panics, and may polarize experts, nations, political parties, organizations and individuals (Beck, 2002).

As a new risk becomes public and political, it is debated, not just in terms of the risk itself, but also in light of its social, economic and political consequences. As a result of the risk society, the precautionary principle has governed risk management. The precautionary principle holds that

The absence of evidence of risk is not evidence of the absence of risk, and that rather than waiting for evidence of harm to be demonstrated before acting, the burden of proof should be shifted to require sponsors of a risky product or activity to demonstrate that it is safe or else be subject to regulatory restriction or ban. (Stern \& Weiner, 2006, p. 394) 
Beck's risk society premise has become a contemporary reality, and as a result risk management has become a growth industry in Western cultures.

Yet, because we are part of the greater social order, how society perceives risk also affects us at the individual level. Durodié (2004b) has argued that "far from this erosion of old community values ... giving rise to a new confident individualism, what we have seen is the emergence of a disconnecting process of individuation. . .. Subjective impressions of reality ... go unchecked, unmediated or unmoderated through membership of a wider group or association" (p. 15). Furedi (2002) posited that we now live our lives guided by a 'precautionary principle'. He believes that risk aversion prevails in virtually every domain of human activity. In his book, Culture of Fear, Furedi (2002) wrote,

Many panics about the environment or technology had a similar structure to today's fear about more mundane matters, such as risky relations between people. Concern with safety is just as intense in the area of personal relations as it is in environmental issues. (p. viii)

He also suggested that the most damaging consequence of the precautionary principle is how risk aversion influences interpersonal behavior, by subjecting personal relations to the calculus of risk (Furedi, 2002). Further, as Altheide (2003) argued:

In addition to propaganda effects, the constant use of fear pervades crises and normal times: it becomes part of the taken-for-granted world of "how things are", and one consequence is that it begins to influence how we perceive and talk about everyday life, including mundane as well as significant events. This produces a discourse of fear, the pervasive communication, symbolic awareness, and expectation that danger and risk are a central feature of everyday life. (p. 38)

\section{Fear and Anxiety}

Risk has now morphed from Beck's global ecological crises to a growing assessment of risk in terms of our personal experiences. As a consequence, to feel safe, many people will disengage from their communities. Withdrawal creates a new spiral of concern because we fear what we do not know. Some writers have gone so far to describe present Western culture as being an "age of anxiety" (Durodié, 2005 , p. 6). Thus, paradoxically, while developed nations are becoming more global in many aspects of life, their populations are becoming more isolated within their local communities.

As Furedi (2002) observes, what is mystifying about this fear is that:

Many of our fears are not based on our personal experiences. Compared with the past, people living in Western societies have less familiarity with pain, suffering, debilitating disease and death than ever before. And yet, despite an unprecedented level of personal security, fear has become an ever expanding part of our life. Western societies are increasingly dominated by a culture of 
fear. The defining feature of this culture is the belief that humanity is confronted by powerful destructive forces that threaten our everyday existence. (p. vii)

This milieu propagates an environment in which violent acts such as terrorism can intensify alarm. Ironically, this fear is what terrorism seeks. As Ericson and Doyle (2004) noted, "terrorists are explicitly in the business of uncertainty. They play on randomness to keep whole populations in fear, anticipation, and disestablishment. They precipitate the urge for more certainty, expressed through escalating security measures" (p. 141). This cycle is illustrated in Figure 1 below.

Thus, it is logical that the 2004 Athens Olympic Games were described as an attractive option for terrorists who wished to communicate their message to a global audience of billions, strike the cradle of Western democracy, and attack Western citizens and interests (Migdalovitz, 2004). This was by no means the first time that the Games have been beleaguered in this manner.

Ericson and Doyle (2004, p. 141) noted that "the terrorist power of uncertainty is especially strong because we do live in a risk society. This society is characterized by a cultural desire to tame chance and effect security and by institutions increasingly organized around risk management' (Garland, 2003). Terrorism strikes at the foundation of a risk society because it is a stark reminder of the limits to risk assessment and management.

In this context, it is not sufficient to manage corporations to optimize production variables, such as profits, productivity, jobs, and growth. Corporations must manage risk variables, such as . . public safety. This type of management does not mean simply an expansion of the management agenda to include new risks. It implies a fundamental reversal in the focus of managers' attention,

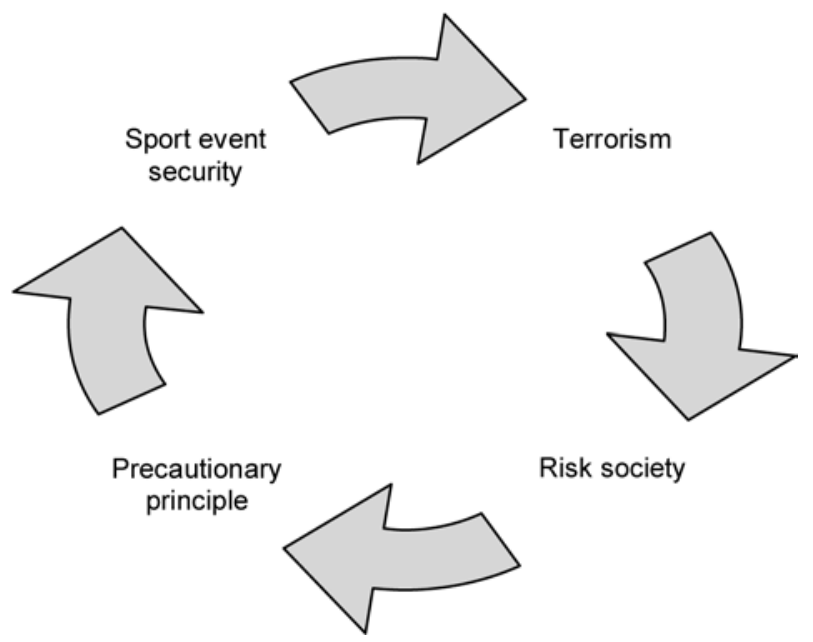

Figure 1-The relationship between terrorism and sport events. 
that is, substituting the production orientation of existing paradigms with the risk orientation of a new paradigm. The traditional management paradigm was developed for the industrial society; thus, it is inherently limited in many ways for meeting the challenges of the "risk" society. (Shrivastava, 1995, p. 123)

The Olympic Games provide a robust example of how the risk society has affected the consumption and management of sport, in regards to their approach to the response to terrorism.

\section{The Olympic Games and the Risk of Terrorism}

Since the advent of satellite television and the resultant juggernaut of Olympic global penetration, the Games' resultant success has made them hostage to political manipulation, including instrumental violence such as terrorism. Since the Black September group's attack on Israeli athletes and officials at 1972 Munich Games, politically motivated violence has had an effect on the Olympic Games on a number of different levels, from the tangible increased security measure costs to what has been quixotically described as the Olympic Games" "loss of innocence" (Moore, 1996, p. 30). The international attention achieved by the attack resonated beyond the sporting milieu. It demonstrated that terrorism could be an effective tactic in challenging governments and raising international awareness of a cause (Johnson, 2001). In keeping with the notion of a risk society, it also meant that responsibility for the attack could be attributed to global forces. Thus, it is no surprise that, in its Official Report to the International Olympic Committee (IOC), the Munich Games Organizing Committee (1974) claimed "that the occurrences of September 5,1972 were possible cannot be blamed on the security service. Its employment and behavior expressed the overall conception of the Olympic Games" (p. 347).

Despite these claims, the Organizing Committee of the XXth Olympic Games in Munich in 1972 had commissioned the president of the Munich police force to advise it on all security matters; organize, supervise, and direct the security service; and award security contracts. In terms of the Olympic Village, the remit of the security force was to protect the Village from trespass by unauthorized persons and provide a general access control function; settle minor disruptions; and intervene in cases of criminal activity; and control traffic (Organizing Committee for the Games of the XXth Olympiad, 1974). This responsibility was not met.

Initial calculations by Games organizers had estimated that the number of Olympic security service employees needed would be in the order of 1,740. As planning became more detailed, it was realized that this number would be insufficient and staffing levels rose to 2,130. This increase in security personnel was insufficient to prevent tragedy, however. On September 5, 1972 at 4:40 a.m., eight Palestinians disguised as Olympic athletes entered the Olympic Village and entered the Israeli team quarters, taking nine hostages and killing two others. The alarm was raised and one hour later, Willi Daume (the President of the Organizing Committee), the Organizing Committee's security authorities, and the Munich police president (Dr. Manfred Schreiber) met. From this point on, the authority to deal with the terrorists was subordinated to the police, who have been blamed for much of the subsequent mishandling of the rescue efforts, when all the remaining 
hostages, a German policeman, and five of the terrorists were killed (Organizing Committee for the Games of the XXth Olympiad, 1974).

There was considerable criticism of the response of Games organizers to their handling of the attack itself and also of its impact on the operation of the Games. For example, despite the fact that Avery Brundage (the President of the IOC), members of the IOC executive board, and Willi Daume were in conference all that day, it was not until 3:30 p.m. that they made a decision to suspend competition (Organizing Committee for the Games of the XXth Olympiad, 1974). The IOC also decided that

The Games would be resumed in the afternoon of September 6, 1972 after a memorial ceremony that morning in Olympic Stadium and the Games would be extended by a day. . . . In addition, the IOC decided to cancel any further receptions during the Games, to end the performances at the "amusement street," and to revise the program of the closing ceremony, giving it a subdued form. (Organizing Committee for the Games of the XXth Olympiad, 1974, p. 36)

Some nations demanded that the Games be cancelled; however, the IOC ruled against this, reasoning that if it did so then the Games would be susceptible to further terrorist attacks. A further criticism of the IOC occurred when, during his speech at the Closing Ceremony, Avery Brundage related the terrorist attack with the issue of Rhodesia's participation. The following day he issued an apology regretting any misunderstanding of his words (Toohey \& Veal, 2000).

The Munich Games organizers had based their security measures on information sourced from similar, large-scale sports events. As a result, their security focus had not been on preventing terrorism, rather it was based on averting demonstrations (such as had occurred at the 1968 Mexico Games). Another factor in their rationale for the security planning and indeed the whole image of the 1972 Games was to ensure that there would be no comparisons with the 1936 Berlin "Nazi Olympics." According to the Official Report, high visibility of German police was still subject to prejudice. As a result, the Games organizers decided there would not be highly visible security and that security fencing and other physical barriers would not be visually forbidding (Organizing Committee for the Games of the XXth Olympiad, 1974).

The Munich massacre was part of the Palestine Liberation Organization's (PLO) overall strategy to bring world attention to its cause. Faud al-Shameli, one of the operation's planners, noted that, "bombing attacks on El Al offices do not serve our cause. . . . We have to kill their most important and famous people. Since we cannot come close to their statesmen, we have to kill artists and sportsmen" (Dershowitz, 2002, p. 41).

Further to the calculated choice of using the Olympic Games, Black September issued the following communiqué a week after the killings:

In our assessment, and in light of the result, we have made one of the best achievements of Palestinian commando action. A bomb in the White House, a mine in the Vatican, the death of Mao Tse-tung, an earthquake in Paris could not have echoed through the consciousness of every man in the world like the operation at Munich. The Olympiad arouses the people's interest and attention more than anything else in the world. The choice of the Olympics, from the 
purely propagandistic viewpoint was $100 \%$ successful. It was like painting the name of Palestine on a mountain that can be seen from the four corners of the earth. (Dershowitz, 2002, p. 46)

In 2006, Mohammad Oudeh (known previously as Abu Dauod), the surviving planner of the Munich attack, remained convinced of its benefits for the Palestinian cause. He commented, "Before Munich, we were simply terrorists. After Munich, at least people started asking 'Who are these terrorists? What do they want?' Before Munich, nobody had the slightest idea about Palestine" (as quoted in Karam, 2006, p. 19).

Since these Games, the Olympics have required far more sophisticated security planning coupled with greater organizational complexity as they have involved national and international collaboration between security organizations. These measures will be discussed in relation to the remaining Games. The result has meant more complex logistics, increasing cost for organizers and some Draconian effects for athletes, officials, and spectators. For example, Johnson (2006) attributed the blowout in the Montréal Games budget from $\$ 310$ to over $\$ 1.5$ billion in part to the additional security arrangements needed.

Security planning for the Montréal Games was led by the Montréal Urban Community Police Department (MUCPD), assisted by the Québec Police Force (QPF) and the Royal Canadian Mounted Police (RCMP). In addition to police in uniform, plainclothes officers were assigned to detection and infiltration activities. In addition, there was a strong presence of uniformed and armed members of the Canadian Forces. Civilian guards were used for crowd control and information services. During the Games operations, a total of 17,224 policemen, members of the military, and civilian guards were involved. The Organizing Committee, as part of its planning, also formed a Security Intelligence Services Subcommittee. This comprised members from the RCMP, the MUCPD, the QPF, and the Canadian Forces intelligence services. Among its tasks were "to undertake special studies of risk, conflict, terrorism, etc." (Organizing Committee for the Olympic Games (COJO), 1978, p. 562).

The most evident result of the new security paradigm was that armed guards and police were now conspicuous at venues and in the host city. This adjustment did not meet with universal public approval, however. Before the Games, there were fears that "over-strict security measures would encourage the security agencies to commit excesses, thereby perhaps violating people's civil rights and liberties" (Organizing Committee for the Olympic Games (COJO), 1978, p. 570). Although these fears were unfounded, the strong security presence caused some critics to object that it was practically impossible to come into close contact with the athletes even in the areas specially set aside for meetings (Organizing Committee for the Olympic Games (COJO), 1978).

Another outcome of the Munich attack was that accredited athletes and officials were subjected to much tighter security checks before entering Olympic venues, and individuals without accreditation were excluded. The Montréal Games security was so intrusive that the organizers received many complaints about the different arrangements. Despite these complaints, the security framework developed for the Montréal Games has provided the paradigm for all ensuing Olympic security operations (Kennelly, 2005). Although it has prevented some attacks, it has not prevented a variety of terrorist groups from targeting subsequent Games. 
After South Korea was selected as the site of the 1988 Olympic Games, North Korea demanded that it cohost the event. Their demands were rejected. Following this rebuff, two fatal bombings were linked directly to North Korean efforts to disrupt Games' preparations. Revelations throughout 1988 about North Korea's complicity in the bombing of a South Korean airliner in November 1987 possibly served to prevent the country from any further attempts to create disorder at the Games (Pound, 1994). Subsequent to the inauguration of Roh Tae Woo as South Korean president, in February 1988, both Japan and the United States provided direct security assistance to Korea to ensure that the Games would be secure. Japan (base of the terrorist group, The Red Army, which had made threats against the Games) monitored thousands of airline flights and visitors passing through Tokyo and other Japanese cities en route to the Olympic city; the U.S. deployed additional air, naval, and security units in and around South Korea before and during the Games (Pound, 1994).

In 1992, two Spanish terrorist groups endeavored to disrupt the Barcelona Games Opening Ceremony by bombing utility supply routes. At the 1996 Atlanta Games, a bomb planted by a lone American antiabortion extremist in Centennial Park killed one spectator, resulted in a journalist covering the event dying of a heart attack, and injured over 100 more spectators. These instances demonstrated that terrorism at an Olympic Games did not have to occur within the confines of the sporting venues to impact the Games.

As part of the security preparations for the following Games, held in Sydney, an Olympic Intelligence Center was created within the organizing committee to provide intelligence-based risk management and identify and prioritize all Gamesrelated risks. The center had strong links with the Australian Security Intelligence Organization (ASIO) (Toohey, 2001). Despite the fact their reports indicated that terrorism threats to the Games were considered to be slight, precautions were taken to prevent the four potential sources of attack identified: "state agents of terror, formalized terrorist groups, loosely affiliated extremists, and lone militants" (The Terrorism Research Centre, 2000, p. 1). Islamic extremists, especially groups associated with Osama Bin Laden, such as al-Qaeda, were listed as one of the loosely affiliated extremist threats. Two alleged terrorist attempts were prevented in their planning stages. In 2000, New Zealand police foiled a suspected plot to target Lucas Heights Nuclear Reactor during the Sydney Olympic Games. During an investigation into people smuggling, Auckland police raided a house and found evidence suggesting the scheme. At the time it was thought possible that Bin Laden was associated with the plot. In May 2000, a man whose home was discovered packed with explosives was arrested near the Olympic site, and then, during the following month, Australian authorities deported five people linked to extremist groups (Operation Olympics: Sydney Is Ready for Terrorists, 2000). These were the last Olympic Games before 9/11.

Since the 9/11 terrorism attacks in the United States, the concern of terrorism at mega-sporting events has been amplified (Toohey, Taylor, \& Lee, 2003), even though there was no specific sport connection to the event itself. Olympic organizers have spent considerably more on security measures, and the perceived risk of terrorism has been cited as a reason for low spectator numbers at the 2004 Olympic Games and an influence on the experiences of those who attended (Cashman, 2004; Taylor \& Toohey, 2006). 
The changes to security after 9/11 were clearly evident at the 2002 Salt Lake City Winter Olympic Games. Soon after the 9/11 tragedy there was a reevaluation of the event's security procedures (Diaz, 2001). A press statement released by the White House outlined the new approach to Games security as "highly visible equals highly secure" (Kennelly, 2005; Office of the Press Secretary, 2002). As part of the associated strategy, airport security was increased and airspace restricted. The Organizing Committee acquired 15,000 antianthrax tablets, and the State of Utah commissioned the design and implementation of health monitoring systems to detect and manage possible incidents of bioterrorism. Biometric scanners were used to identify accredited officials and athletes, and vehicles were prohibited within 300 feet of venues and other selected buildings. In total, there were 60 different federal, state, and local agencies, and over 15,000 people, including 10,000 National Guardsmen, involved in Games-related security operations (Kennelly, 2005; Snider, 2002). It is estimated that the September 11 attacks resulted in an additional US\$70 million spending on Games' security, bringing the total security budget to around US\$500 million (Snider, 2002). This amount was more than double that of the 1996 Atlanta Summer Olympic Games (Wicks, 2002), but far less than that of the next Games, the 2004 Athens Olympic Games.

\section{Safety and Security Management for 2004 Athens Olympic Games}

The Athens Games have been estimated to have spent over $€ 1.2$ billion (US $\$ 1.85$ billion) on safety measures, a considerable increase on the original budget of $€ 300$ million (US\$463 million) (Maditinos, Vassiliados, \& Charlebois, 2006) and more than $10 \%$ of the overall Games budget (Johnson, 2006). Despite extensive preparations, in the lead-up to the Athens Olympic Games, Greek officials were continually called on to reassure the world of their security preparedness. This was particularly evident after several incidents of domestic and international terrorism in and close to Greece. Early in 2004, two Greek government vehicles were firebombed, coinciding with a visit from the International Olympic Committee (IOC) President, Jacques Rogge (Kennelly, 2005). A local group claimed responsibility for the attack and described it as a protest against the Games and revenge for workers killed in accidents on Olympic construction sites. Then, 100 days before the Opening Ceremony, three bombs exploded in Athens (Kennelly, 2005). Although no one was harmed in either of these attacks, they signaled that terrorism was a distinct possibility during the Games.

An unrelated terrorist incident, the bombing of a peak hour commuter train in May 2004, in Madrid, Spain, which killed approximately 200 people, also signaled concern for Olympic organizers (Kennelly, 2005). Although Spanish authorities initially blamed the Basque separatist group, ETA, it was subsequently discovered that the attack in Madrid was the work of a loose-knit terrorist group, allegedly linked to al Qaeda and related to Spain's involvement in the invasion of Iraq. This led to the suggestion that athletes from countries with troops in Iraq could be targeted in Athens at the Olympic Games (Rufford, 2004). Although the IOC acknowledged that these bombs raised security concerns, they announced that they had complete confidence in the security planning for Athens. Similar to previous Games, overall responsibility for the security of the Games resided outside the 
organizing committee itself. For Athens, it rested with the Hellenic Police, under the Ministry of Public Order. A dedicated unit, the Olympic Game Security Division (OGSD), was created. It was staffed by personnel from the police, coast guard, fire brigade, and defense forces, and reported directly to the chief of police. An Olympic Intelligence Center responsible for assessing threats was also created. It shared information with over 150 countries (Maditinos et al., 2006). Altogether approximately 41,000 security personnel worked at the Games; this was a huge increase on the 2,130 security staff at the 1972 Munich Games and a threefold increase over the Sydney Games.

In addition, Greece had accepted security planning, training, and intelligence assistance from the first-ever international Olympic security team, known as the Olympic Advisory Group (OAG). This unit included members from Great Britain, Germany, the United States, Spain, France, Australia, and Israel. It met regularly to discuss planning, technology, and training issues. Within this framework, the Games organizers held operational readiness exercises with British police, as well as specialized training sessions with other foreign government agencies represented on the OAG (Kennelly, 2005). Moreover, the Greeks also received assistance from the North Atlantic Treaty Organization (NATO) (Kennelly, 2005).

The Olympic Village was guarded by an Olympic Village Security Command Center, which employed state-of-the-art security. Other Games-specific security planning and operations included border surveillance; air space protection; urban domain security; fire safety; terrorist activities response; and chemical, biological, radiological, and nuclear threat responses (Maditinos et al., 2006). Even so, some security analysts were not convinced of the results of this planning and claimed that the Greek government and Games organizers were downplaying the risks, despite the fact that Greece had passed antiterrorism legislation and implemented unprecedented security planning (Kennelly, 2005). Organizers were also faced with possibility of team withdrawals. It was rumored that the United States team would pull out if the perceived threat of terrorism was too high (Dahlberg, 2004). In the face of this criticism, Athens Mayor Dora Bakoyianni noted, "We are paying the price for September 11” (Lui, Vlahou, \& Robert, 2004, p. 22).

Regardless of IOC and Games organizers' assurances, the Australian government was not convinced of safety measures and caused an altercation with Greek Olympic officials by issuing warnings about traveling to Greece. Athens Olympic Organizing Committee (ATHOC) President Gianna Angelopoulos-Daskalaki was unconvinced of the merits of the concerns emanating from the country of the "best ever Games" (Toohey, 2006). She was quoted as saying, "Australia chose, in the very middle of an overwhelmingly successful IOC Coordination Commission meeting, to release a warning about traveling to Greece. This is damaging to the Olympic Games" (Athens Olympic Organizing Committee, 2004).

At Games time, the security force included tens of thousands of trained personnel, fighter jets, and airborne surveillance. Its arsenal included Patriot, Stinger, and Hawk missiles. There was naval and port security. Athens 2004 turned out to be the most guarded Olympic Games in history and the "biggest, most expensive peacetime security operation ever" (Wilson, 2004). Despite, or perhaps because of, all the pre-Games safety concerns, there were no major terrorism incidents during the event. The most tragic security-related episode occurred when a security guard, who was playing Russian roulette while on duty, killed himself. 


\section{Fear and the Precaution Principle: The Case of Athens}

Safety and security planning has always been a key function of stadium and arena management, with "venue managers needing to keep their venues safe and secure within a broad risk management perspective" (Sweaney, 2005, p. 22). In the current culture of fear, much has been made of the possibility that mega-sports-event attendance might be an activity that people choose to pass up because of their perceptions of risk. Alternatively, sport event attendance can be used to publicly demonstrate attendees' resistance to terrorism and resilience to fear and anxiety.

A study by Toohey and Taylor (2005) at the 2004 Olympic Games investigated the reasons why attendees chose to attend the Athens Games and their perceptions of safety and security concerns. Of the 277 Olympic Games attendees they surveyed, $21 \%$ had considered not coming to Athens because of safety concerns, and $12 \%$ indicated that feeling safe was an important consideration in their decision to attend. When asked why they chose to still come despite concerns, their responses were grouped into four categories, "Defiants" (with statements such as "Not willing to live in fear or put my life on hold"), "Precautionaries" ("We have confidence in the security"), "Blind Devotees" ("I love the Olympic Games too much not to come"), and "Indifferents" ( "I still got to live life" and "You could die anywhere").

The research reported that $24 \%$ of respondents indicated that they did not feel safe during the event. Men, more than women, felt security measures detracted from their Olympic experience. All of the attendees classified as "Blind Devotees" noted safety as "unimportant" in their decision to attend the event. Attendees from Greece, Ireland, Germany, and France were more likely to place low levels of importance on safety aspects and to indicate that Games' related security detracted from their Olympic experience. On the other hand, attendees from China, Japan, and Korea were more likely to report that security enhanced their experience and attached a high level of importance on safety and security procedures. These findings suggest gender and cultural differences in expectations of event security and perceptions of risk.

Toohey and Taylor (2005) listed the respondents' suggestions for 'bestpractice" in sport event safety and security management under five categories: visibility (e.g., "Security needs to be seen"); resilience (e.g., "Be tough on terrorists"); communication (e.g., "Brief spectators in advance" and "Ensure the [host] language plus English is understood by security"); restraint/caution (e.g., "Don't judge spectators by their ethnic appearance"; and minimalism (e.g., "Security is too much," and "too intrusive"). This list is reflective of the different expectations and perceptions of risk and safety of event attendees.

Another consideration is the level at which safety and security is conceptualized. For example, security can be viewed from the individual's perspective if they are attending the event on their own; from a group perspective if they are traveling with others; and from a community context, that is all the attendees or all the local residents next to the venue (Trim \& Caravelli, 2007). The type of risk that each perceives as relating to them and how likely it is that this risk will materialize adds another layer to our analysis.

Taking the information we have about the Games organizers' approaches to risk management and attendee data, we posit that the Athens case is illustrative of the general tenets of Beck's (1992) premise for a risk society. In particular, the 
increased public commitment to prevent risk and focus on safety is evident in the global involvement in the provision of risk management support via physical and human resources, technology, and knowledge transfer to accompany the massive infusion of funds by the Greek organizers. The use of such an extensive range of risk management initiatives, taken together with the press releases and public information measures issued by the event organizers, suggest that the precautionary principle and risk aversion (Furedi, 2002) pervaded the event planning process. On the other hand, Games attendees, by the mere virtue of their presence in Athens, defied the risk society's predictions of overt anxiety and fear. Atheide's (2003) discourse of fear was manifest in a small proportion of the event attendees and was reflected via the 'precautionaries' category reported by Toohey and Taylor (2005). A large number of attendees also demonstrated, however, that their lives were not framed by danger. This latter group of Athens 2004 visitors included the aggressively anti-fear "defiants," the "blind devotees" who noted that they would attend the Olympic Games regardless of external contexts, and the cynical "indifferents" who were summarily dismissive about the threat of terrorism at the Games.

\section{Fear, Precaution, Defiance, and Indifference to Terrorism}

Since 9/11, the threat of the appropriation of the Olympic Games as a site of terror, at the operational level, has resulted in a positive backlash of increased governmental cooperation and multinational networking. These responses are clearly in line with Kenny's (2004) contention that there is a perceived need to develop strategies to confront risk and lives framed by danger. Although the risk society has pervaded sport event attendance, its diffusion is far from complete.

As we have seen at Athens 2004, not all members of the public engaged with the precautionary principle and presumably even those that did might soon object to being searched in an intrusive way, or subject to tight security demands (Sweaney, 2005). Therefore, the choice of safety and security methods to be used at megasporting events, especially at the Olympic Games, is open to reconceptualization and repositioning. Although there is a legitimate and important place for risk management and technology in sport event management, Games organizers also need to understand the range of emotional responses by consumers to these solutions and the reasons for both positive and negative reactions. As Durodié (2004a) argues, too much reliance on technical solutions can actually heighten the sense of risk.

Perhaps sport can offer one of the best sites of resistance to risk society's confines if event organizers address the issue of how to strike an acceptable balance between the risk management necessities created by and through the precautionary principle and the cycle of cynicism and disengagement created by the culture of fear. This proposition requires more field-based research to explore these issues across different events, countries and contexts. According to Elliot et al. (1999),

Safety is important in all sectors of the sports and leisure industry. The complacency which is shattered only by the occasional disaster and radical change needs to be replaced by a marked willingness to seek out and adopt best practice, informed by the results of relevant research. (p. 26) 
There are a number of ways that empirical research in this area can be used to develop better event-based operational procedures, as well as enhancing macro-level strategies in the current terrorism-alert risk society. First, there is the value of using theory that emanates from another discipline such as overviewed here, to better understand sport-specific, mega-event attendance. There is also a need to develop a sport-focused research agenda in this area (Chalip, 2006), that is, uncovering theory that is specifically grounded in the sport phenomena but which can then have relevance to other industries (such as tourism). From the results of these foci, mega-sport event organizers can then work towards ensuring that spectators have positive and safe experiences. These experiences should be grounded in understanding the cultural contexts of the consumers as well as the host city and nation. The management of risk should not be exclusively based on technological solutions that might ultimately exacerbate spectators' perception of risk and decrease their desire to attend the Games.

There is a real prospect of government and Olympic organizers overreacting and expending excessive resources on counter-terrorism actions. The cost of such measures will further limit the number of nations able to afford staging Olympic Games. There is also a danger of risk amplification whereby the message above the level of risk is accelerated by the media, government, experts, pressure groups, and the like. Thus there is a need to approach risk management, fear minimization, and precautions sensibly. In this respect, the amount and type of information communicated to the general public should be regulated and monitored to avoid unnecessary escalation of fear. It is important also to distinguish between uncertainty and risk so that presence of the associated security measures can be adequately conveyed to potential and actual sport event attendees. Similarly, the political climate and cultural practices of the host nation need to be taken into consideration to be inclusive of non-Western nations.

The host's ability to effectively manage safety-related terrorism concerns across the spectrum of Olympic stakeholders will be very relevant to the 2008 Olympic Games to be staged in Beijing and of course in London in 2012. The July 7, 2005 attacks in London and subsequent spoiled terrorism acts have left many residents wary of future attacks. The Olympic Games organizers, participants, media, companies and businesses, governmentalities, and other organizations associated with the event will need to work together to ensure a successful collective approach to managing risk perceptions and promoting enjoyment of the Games that leaves all stakeholders with a positive and rewarding legacy.

\section{Acknowledgments}

The authors gratefully acknowledge the financial support provided by the University of Technology, Sydney to conduct this research.

\section{References}

Agence France-Presse. (2005, May, 26). Counter-terror spending to hit $\$ 25$ bn. News. com.au. Retrieved September 02, 2006, from http://www.news.com.au/story/ print/0,10119,15410985,00.html 
Altheide, D.L. (2003). Notes towards a politics of fear. Journal for Crime, Conflict and the Media, 1(1), 37-54.

Amis, J., \& Silk, M.L. (2005). Promoting critical and innovative approaches to the study of sport management. Journal of Sport Management, 19, 355-366.

Athens Olympic Organizing Committee. (2004). International Olympic security conference. Retrieved June 17, 2006, from www.athens2004.com

Atkinson, M., \& Young, K. (2002). Terror games: Media treatment of security issues at the 2002 Winter Olympic Games. OLYMPIKA: The International Journal of Olympic Studies, XI, 53-78.

Beck, U. (1992). Risk society: Towards a new modernity (M. Ritter, Trans.). London: Sage Publications.

Beck, U. (2002). The silence of words and political dynamics in the world risk society. Logos, 1(4), 1-18.

Cashman, R. (2004, August 27). Athens 2004: The no show game. National Forum Online; Online Opinion. Retrieved August 27, 2005, from http://www.onlineopinion.com.au

Chalip, L. (2006). Towards a distinctive sport management discipline. Journal of Sport Management, 20, 1-21.

Clark, K. (2004, June 14). Targeting the Olympics. U.S. News and World Report, p. 34.

Coaffee, J., \& Wood, D. (2006). Security is coming home: Rethinking scale and constructing resilience in the global urban response to terrorist risk. International Relations, 20, 503-517.

Constitutional Rights Foundation. (2006). America responds to terrorism: what is terrorism? Retrieved June 17, 2006, from http://www.crf-usa.org/terror/America\%20Responds\%20 to\%20Terrorism.htm

Dahlberg, P. (2004, May 7). U.S. debates on sending team to Athens Olympics. Retrieved October 13, 2004, from http://www.thebatt.com.news/2004/05/07/Sports/u

Dershowitz, A.M. (2002). Why terrorism works: Understanding the threat, responding to the challenge. New Haven: Yale University Press.

Diaz, G. (2001, November 12). Olympics stress safety: Salt Lake City officials will reevaluate the safety measures of the 2002 Olympic Games. Retrieved May 30, 2004, from http:// search.epnet.com/direct/asp? $=2 \mathrm{~W} 73967318095 \& \mathrm{db}=\mathrm{nfh}$

Durodié, B. (2004a). The limitations of risk management: Dealing with disasters and building social resilience. Tidsskriftet Politik, 8(1), 14-21.

Durodié, B. (2004b). Panic in the streets. New Humanist, 119(3), 18-19.

Durodié, B. (2005). Cultural precursors and psychological consequences of contemporary Western responses to acts of terror. In S. Wesseley \& V. Krasnov (Eds.), Psychological responses to the new terrorism: NATO-Russia dialogue (pp. 37-53). Amsterdam: IOS Press.

Elliot, D., Frosdick, S., \& Smith, D. (1999). The failure of 'legislation by crisis'. In S. Frosdick \& L. Walley (Eds.), Sport and safety management (pp. 11-30). Oxford: Butterworth Heinemann.

Ericson, R.V., \& Doyle, A. (2004). Uncertain business: Risk, insurance and the limits of knowledge. Toronto: Toronto University Press.

Frosdick, S. (1999). Beyond football hooliganism. In S. Frosdick \& L. Walley (Eds.), Sport and safety management (pp. 3-10). Oxford: Butterworth Heinemann.

Furedi, F. (2002). Culture of fear. London: Continuum.

Garland, D. (2003). Risk and morality. Toronto: University of Toronto.

Giddens, A. (1998). Risk society: The context of British politics. In J. Franklin (Ed.), The politics of risk society (pp. 24-34). Cambridge: Polity Press.

Hall, C.M., Timothy, D.J., \& Duval, D.T. (2003). Safety and security in tourism: Relationships, management, and marketing. New York: Haworth Hospitality Press. 
Hadfield, W., Toohey, K., Taylor, T., \& Mason, S. (Writer) (2004). No Rain Stops Play How the drought is hurting rural sport [Radio]. Sports Factor. Australia: ABC Radio National.

Johnson, C. (2006). A Brief Overview of Technical and Organisational Security at

Olympic Events. Unpublished document. Retrieved March 18, 2007, from www.des.gla. ac.uk/ johnson/papers/CW_Johnson_Olympics.pdf+olympic+terror+plan

Johnson, L. (2001). The future of terrorism. American Behavioral Scientist, 44, 894-913.

Karam, Z. (2006, February 25-26). Olympics snub that led to Munich bloodbath. Sydney Morning Herald, p. 19.

Kennelly, M. (2005). 'Business as usual': How elite Australian athletes frame terrorism post 9/11. Unpublished bachelor honours thesis, University of Technology, Sydney: Sydney: New South Wales.

Kenny, S. (2004, November 3). Risk and contemporary life. Paper presented for Professional lecture, Deakin University. Retrieved September 17, 2006, from http://www.deakin. edu.au/arts/Uploads/Risk\%20and\%20Contemporary\%20Life.pdf.

Kiras, J. (2005). Terrorism and globalisation. In J. Baylis, \& S. Smith (Eds.), The globalisation of world politics: An introduction to international relations (pp. 479-498). Oxford: Oxford University Press.

Lui, M., Vlahou, T., \& Robert, M. (2004, March 8). Olympic insecurity. Newsweek International, p. 22.

Maditinos, Z., Vassiliadis, C., \& Charlebois, S. (2006). Mega events: Challenges for contingency planning, opportunities for tourist promotion, International Journal of Information Management, 13, 315-325.

Migdalovitz, C. (2004). Greece: Threat of Terrorism and Security at the Olympics, Congressional Research Service Report for Congress, April 30: 1-6.

Moore, K. (1996, May 8). Munich's message. Sports Illustrated, 85, 30-31.

Office of the Press Secretary. (2002, January 10). Preparing for the world: Homeland security and the Winter Olympics. The U.S. White House. Retrieved June 20, 2006, from http:// www.whitehouse.gov/news/releases/2002/01/20020110-7.html

Operation Olympics: Sydney is ready for terrorists. (2000, August 28). The New Zealand Herald. Retrieved October 17, 2004, from http://www.nzherald.co.nz/index. cfm?objectID = 149227

Organizing Committee for the Games of the XXth Olympiad. (1974). The official report of the Organizing Committee for the Games of the XXth Olympiad Munich 1972 Volume 1 The organization. Munich: Munich pro Sport.

Organizing Committee for the Olympic Games. (COJO) (1978). Games of the XXI Olympiad Montréal 1976 Official Report. Volume I Organization. Ottawa, Canada: COJO.

Pitts, B.G. (2001). Sport management at the millennium: A defining moment. Journal of Sport Management. 15, 1-9.

Pound, R.W. (1994). Five rings over Korea: The secret negotiations behind the 1988 Olympic Games in Seoul. Boston: Little, Brown and Co.

Richardson, L. (2006). What terrorists want. London: John Murray.

Rubin, A. (2004). Safety, security, and preparing for disaster at sporting events. Current sports medicine reports [1537-890X] 3(3), 141-145.

Rufford, N. (2004, May 9). 24-hour guard for Olympians: Armed forces to protect our stars. The Sunday Telegraph, pp. 1-2.

Shrivastava, P. (1995). Ecocentric management for a risk society. Academy of Management Review, 20(1), 118-137.

Skinner, J., \& Edwards, A (2005). Inventive pathways: Fresh visions of sport management research. Journal of Sport Management 19(4), 404-421.

Snider, M. (2002). Safety in numbers. Maclean's, 115(6), 22.

Spence, K. (2005). World risk society and war against terror. Political Studies, 53, 284-302. 
Stern, J., \& Wiener, J.B. (2006). Precaution against terrorism. Journal of Risk Research, 9, 393-447.

Sweaney, K. (2005). Ready for anything. Australasian Leisure Management, 53, 22-23.

Tarlow, P.E. (2002). Event risk management and safety: John Wiley \& Sons, Inc.

Taylor, T., \& Toohey, K. (2006). Impacts of terrorism related safety and security measures at a major sport event, Event Management, 9(4), 199-209.

The Terrorism Research Centre. (2000). Terrorist threat to the Australian Olympics. TRC Threat Assessment.

Toohey, K. (2006, June). Terrorism, sport and public policy in the risk society. Paper presented at 41st University of Otago Foreign Policy School, Dunedin, New Zealand.

Toohey, K. (Ed.). (2001). The Official Report of the Games of the XXVII Olympiad. Sydney: SOCOG.

Toohey, K., \& Taylor, T. (2005, November). Terrorism and the Olympic Games. Paper presented at the International Society of Sport Sociology Conference, Buenos Aires, Argentina.

Toohey, K., \& Taylor, T. (2006). Here be dragons, here be savages, here be bad plumbing: Australian media representations of sport and terrorism. Sport in Society, 9(1), 71-93.

Toohey, K., Taylor, T., \& Lee, C. (2003). The FIFA World Cup 2002: The effects of terrorism on sport tourists. Journal of Sport Tourism, 8(3), 167-185.

Toohey, K., \& Veal, A.J. (2000). The Olympic Games: A social science perspective. Oxon, UK: CABI.

Trim, R., \& Caravelli, J. (2007). A strategic approach to security management at major sporting events. Paper presented at Sport Business Campus '07. London: Birkbeck Sport Business Centre.

Whisenant, W. (2003). Using biometrics for sport management in a post 9/11 era. Facilities, 21, 134-141.

Wicks, B. (2002, January 18). World Cup fans: hooligans or tourists. Paper presented at the Korean Academic Society of Tourism Management International Conference for Success of the 2002 World Cup, Seoul.

Wilson, S. (2004, April 22). IOC close a deal for cancellation insurance. Retrieved April 22, 2004, from http://slam.canoe.ca/Slam/Olympics/2004Athens/2004/04/19/428832-ap. html 